УДК 519.713

\section{ОЦІНКА ЕФЕКТИВНОСТІ МЕТОДІВ ІДЕНТИФІКАЦІЇ АУДІОСИГНАЛІВ В УМОВАХ ВПЛИВУ ХАОТИЧНИХ ІМПУЛЬСНИХ ЗАВАД ЮДІН О.К., ЗЮБІНА Р.В.}

Оцінюється ефективність розроблених методів ефективної ширини спектра та найбільшої інформаційної ваги основного тону в задачі ідентифікації диктора при наявних завадах. Визначено, що в результаті впливу хаотичних імпульсних завад можливість ідентифікації диктора в бігатоальтернативних задачах прийняття рішення різко знижується при збіганні частоти основного тону мовленнєвого сигналу і початкової частоти імпульсної завади для методу найбільшої інформаційної ваги основного тону. Метод ефективної ширини спектра забезпечує високі показники ідентифікації в умовах впливу такого типу завад для текстозалежної ідентифікації.

Ключові слова: частота основного тону, методи ідентифікації, хаотичні імпульсні завади, ймовірність ідентифікації.

Key words: frequency of the main tone, identification methods, chaotic impulse noise, probability of identification.

\section{1. Вступ}

Стрімкий розвиток інформаційних технологій вимагає розробки нових систем обробки, зберігання, відображення та реєстрації критичних інформаційних ресурсів. Впровадження сучасних інформаційних систем ідентифікації користувача в об'єктах інформаційної діяльності стає необхідним елементом забезпечення інформаційної безпеки підприємства та особистості.

Розроблені методи ефективної ширини спектра $[1,2]$ та найбільшої інформаційної ваги основного тону дозволяють проводити ідентифікацію диктора в умовах високого рівня завад. Однак для визначення якісних показників розроблених методів дослідження проводились при моделюванні завад за законом Гаусівського розподілу [3]. Використання такого шуму класичне в системах обробки мовленнєвих сигналів, однак зважаючи на те, що в основі розроблених методів лежать частотні характеристики формування мовленнєвого сигналу, доцільним було б врахувати можливу наявність завад іншого характеру. Відмінним видом завад $є$ хаотичні імпульсні завади, які формуються з урахуванням початкової частоти. Використання хаотичної імпульсної завади з заданою частотою $f_{0}$ може вплинути на якість роботи методів ідентифікації та верифікації у випадку, коли вона точно збігається $з$ частотою основного тону голосу диктора, який підлягає обробці. Таким чином отримаємо задачу оцінки якості розроблених методів в умовах наявності хаотичних імпульсних завад 3 частотою, що майже точно збігається з частотою основного тону голосу диктора $f_{0} \approx f_{\text {чот }}$.

\section{2. Основна частина}

Математична модель хаотичної імпульсної завади має вигляд:

$$
H I N=\sum_{k=0}^{N_{n}-1} \sum_{n=0}^{N_{u}-1} f\left[\begin{array}{l}
t_{3}+\frac{T_{n}}{N_{u}} \cdot n+P \cdot k \leq t_{i}<t_{3}+\frac{T_{n}}{N_{u}} \cdot(n+1)+P \cdot k, \\
f n d(1) \geq 0.5, \\
S m \cdot A \cos \left[2 \pi f_{0} t_{j}+\left.\varphi_{n}\right|_{\varphi_{n}=X_{n} n o r m(N, M, D)}\right], \\
0
\end{array}\right\}
$$

де $t_{3}$ - інтервал затримки кодової конструкції; $N_{u}$ - кількість імпульсів; $T_{n}-$ тривалість кодової конструкції; $N_{n}$ - кількість конструкцій; $P$ - період повторень конструкцій; $\varphi_{n}$ - випадковий фазовий зсув, який генерується випадковим чином [4].

В результаті маємо часове представлення згенерованих хаотичних імпульсів, які будуть виступати як завади.

Результатом додавання інформаційного сигналу Sh02 та створеної послідовності завад стала адитивна суміш Sh01 (рис.2.)

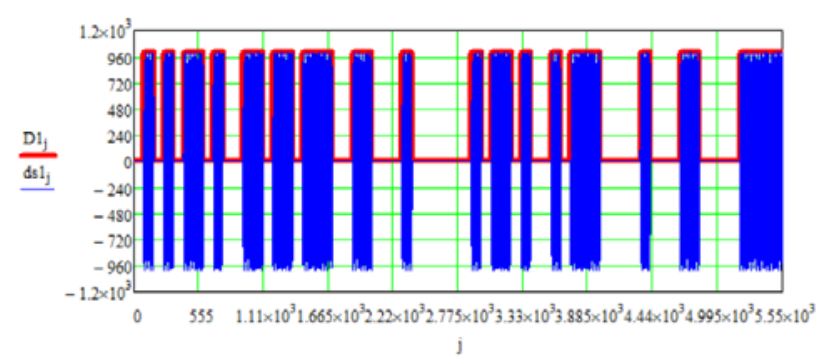

Рис.1. Часове представлення згенерованої послідовності випадкових імпульсних завад

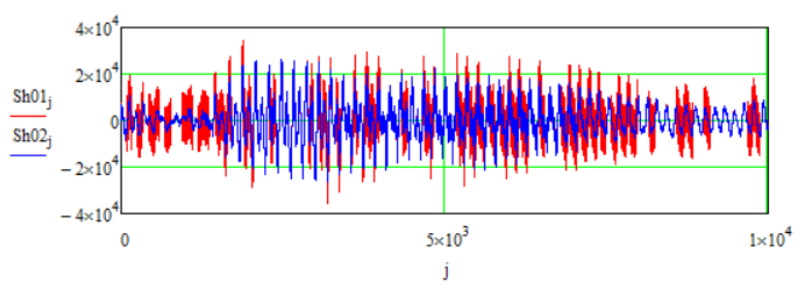

Рис. 2. Часове представлення адитивної суміші Sh01 та інформаційного сигналу Sh02

Для оцінки якості розроблених методів ефективної ширини спектра та найбільшої інформаційної ваги частоти основного тону було обрано показники співвідношення $S N R$, які обраховувались для оцінки ефективності розроблених методів при використанні білого шуму (табл. 1, 2). 
Таблиця 1

Визначення ймовірності вірної ідентифікації диктора в багатоальтернативних задачах підтримки прийняття рішення при $H=8$

\begin{tabular}{|c|c|c|c|c|}
\hline \multirow[b]{2}{*}{$\begin{array}{l}\text { SNR, } \\
\text { дБ }\end{array}$} & \multicolumn{2}{|c|}{$\begin{array}{c}\text { Метод ефективної } \\
\text { ширини спектра }\end{array}$} & \multicolumn{2}{|c|}{$\begin{array}{c}\text { Метод найбільшої } \\
\text { інформаційної ваги } \\
\text { основного тону }\end{array}$} \\
\hline & $\begin{array}{c}\text { Текс- } \\
\text { тоза- } \\
\text { лежна } \\
\text { іден- } \\
\text { тифі- } \\
\text { кація }\end{array}$ & $\begin{array}{c}\text { Текстоне- } \\
\text { залежна } \\
\text { ідентифі- } \\
\text { кація }\end{array}$ & $\begin{array}{c}\text { Тексто- } \\
\text { залежна } \\
\text { ідентифі- } \\
\text { кація }\end{array}$ & $\begin{array}{c}\text { Текстоне- } \\
\text { залежна } \\
\text { ідентифі- } \\
\text { кація }\end{array}$ \\
\hline$-2,9$ & 1 & 0,22 & 0,34 & 0,079 \\
\hline $\begin{array}{c}- \\
5,23\end{array}$ & 1 & 0,275 & 0,335 & 0,127 \\
\hline $\begin{array}{c}- \\
6,67\end{array}$ & 0,99 & 0,25 & 0,3 & 0,05 \\
\hline $\begin{array}{c}- \\
7,88\end{array}$ & 0,99 & 0,22 & 0,29 & 0,14 \\
\hline$-8,9$ & 0,99 & 0,216 & 0,258 & 0,15 \\
\hline $\begin{array}{c}- \\
10,18\end{array}$ & 0,96 & 0,109 & 0,25 & 0,14 \\
\hline $\begin{array}{c}- \\
11,52 \\
\end{array}$ & 0,94 & 0,22 & 0,202 & 0,08 \\
\hline $\begin{array}{c}- \\
12,65 \\
\end{array}$ & 0,79 & 0,16 & 0,205 & 0,12 \\
\hline- & 0,63 & 0,12 & 0,185 & 0,12 \\
\hline $\begin{array}{c}- \\
16,15\end{array}$ & 0,57 & 0,094 & 0,18 & 0,12 \\
\hline
\end{tabular}

У випадку, коли у експерименті бере участь 8 гіпотез, показники вірної ідентифікації свідчать про високі результати при використанні методу ефективної ширини спектра (МЕСШ), так як порівняння гіпотез проходить шляхом аналізу і послідовного перебору всіх інформативних складових спектра, і тільки для текстозалежної ідентифікації.

У випадку методу найбільшої інформаційної ваги основного тону (МНIBОТ) при такій кількості гіпотез метод не справляється з поставленою задачею. Основною причиною таких результатів є залежність від частоти основного тону $f_{\text {чот }}$, яка у даному випадку приблизно дорівнює $f_{0}$.
Таблиця 2

Визначення ймовірності вірної ідентифікації диктора в багатоальтернативних задачах підтримки прийняття рішення при $H=6$

\begin{tabular}{|c|c|c|c|c|}
\hline \multirow[b]{2}{*}{$\begin{array}{l}\text { SNR, } \\
\text { дБ }\end{array}$} & \multicolumn{2}{|c|}{$\begin{array}{c}\text { Метод ефективної } \\
\text { ширини спектра }\end{array}$} & \multicolumn{2}{|c|}{$\begin{array}{c}\text { Метод найбільшої } \\
\text { інформаційної ваги } \\
\text { основного тону }\end{array}$} \\
\hline & $\begin{array}{c}\text { Текс- } \\
\text { тоза- } \\
\text { лежна } \\
\text { іден- } \\
\text { тифі- } \\
\text { кація }\end{array}$ & $\begin{array}{l}\text { Текстоне- } \\
\text { залежна } \\
\text { ідентифі- } \\
\text { кація } \\
\end{array}$ & $\begin{array}{c}\text { Тексто- } \\
\text { залежна } \\
\text { ідентифі- } \\
\text { кація } \\
\end{array}$ & $\begin{array}{c}\text { Текстоне- } \\
\text { залежна } \\
\text { ідентифі- } \\
\text { кація }\end{array}$ \\
\hline$-2,9$ & 1 & 0,139 & 0,18 & 0,15 \\
\hline $\begin{array}{c}- \\
5,23\end{array}$ & 1 & 0,25 & 0,23 & 0,25 \\
\hline $\begin{array}{c}- \\
6,67 \\
\end{array}$ & 0,99 & 0,35 & 0,24 & 0,26 \\
\hline $\begin{array}{c}- \\
7,88 \\
\end{array}$ & 0,99 & 0,33 & 0,35 & 0,18 \\
\hline$-8,9$ & 0,99 & 0,304 & 0,325 & 0,21 \\
\hline $\begin{array}{c}- \\
10,18\end{array}$ & 0,98 & 0,27 & 0,36 & 0,315 \\
\hline $\begin{array}{c}- \\
11,51 \\
9\end{array}$ & 0,84 & 0,114 & 0,32 & 0,17 \\
\hline $\begin{array}{c}- \\
12,65\end{array}$ & 0,84 & 0,19 & 0,23 & 0,17 \\
\hline $\begin{array}{c}- \\
14,6\end{array}$ & 0,47 & 0,07 & 0,197 & 0,114 \\
\hline $\begin{array}{c}- \\
16,15\end{array}$ & 0,37 & 0,1 & 0,226 & 0,18 \\
\hline
\end{tabular}

Таким чином, використання методу найбільної інформаційної ваги основного тону не $\epsilon$ ефективним для ідентифікації диктора в умовах наявності хаотичних імпульсних завад в інформаційній системі надання IT послуг.

Наглядний результат роботи розроблених методів для $H=8$ представлено на рис. 3 .

Використання розроблених методів для багатоальтернативної задачі ідентифікації диктора в умовах наявних хаотичних імпульсних завад при $H=6$ (рис. 4) показало, що як і в попередньому експерименті високі показники дає метод ефективної ширини спектра для текстозалежної ідентифікації, а у випадку методу найбільшої інформаційної ваги основного тону ідентифікація залишається малоймовірною в зв'язку із значним впливом завади на частоту основного тону. 


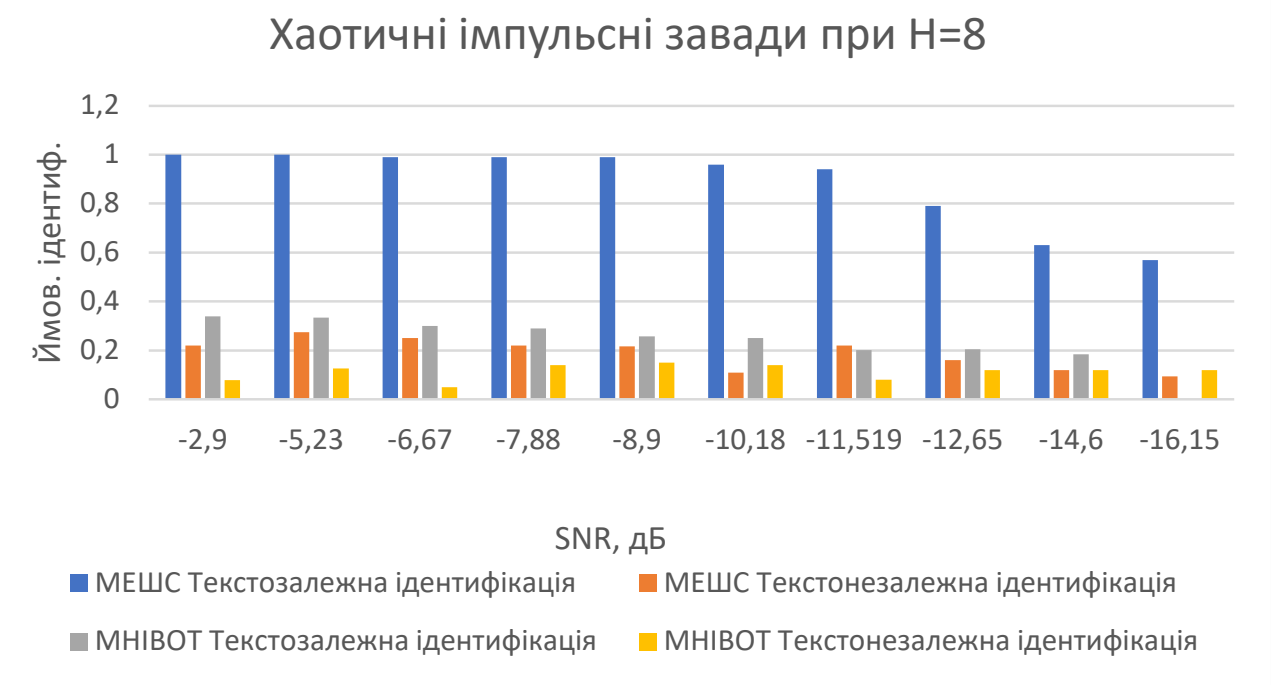

Рис. 3. Показники ймовірності вірної ідентифікації диктора при хаотичних імпульсних завадах розробленими методами при $H=8$

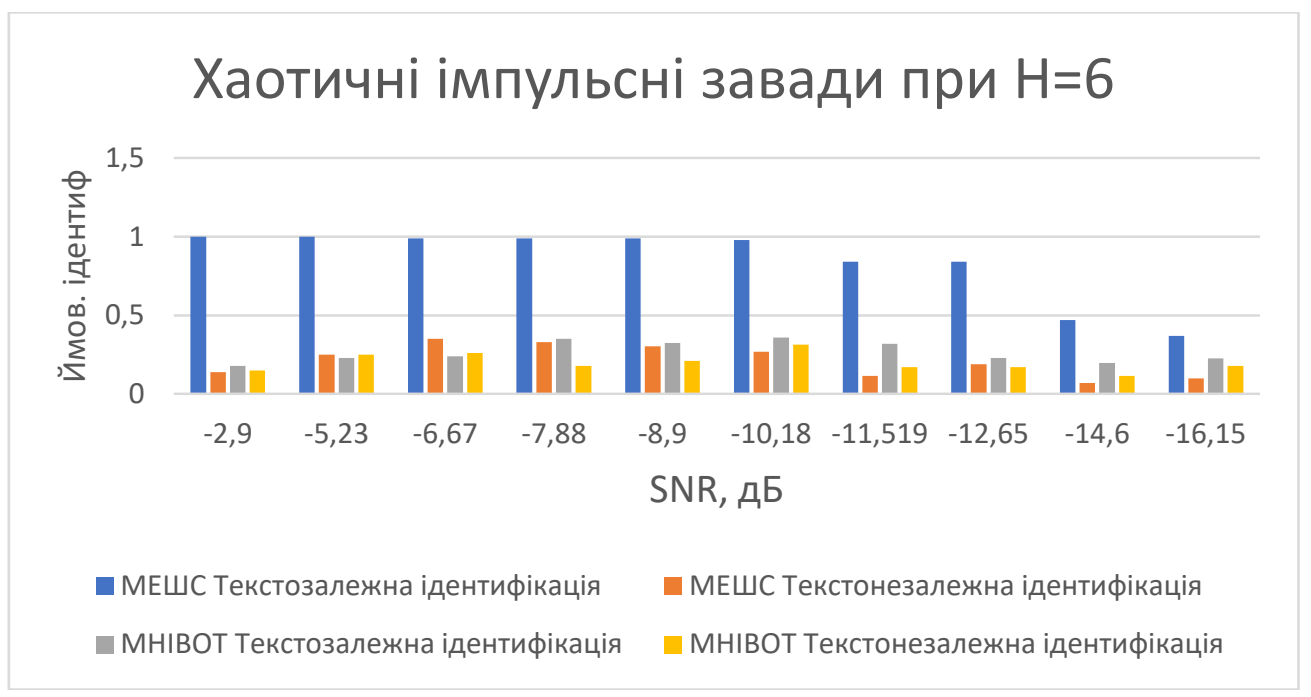

Рис. 4. Показники ймовірності вірної ідентифікації диктора при хаотичних імпульсних завадах розробленими методами при $H=6$

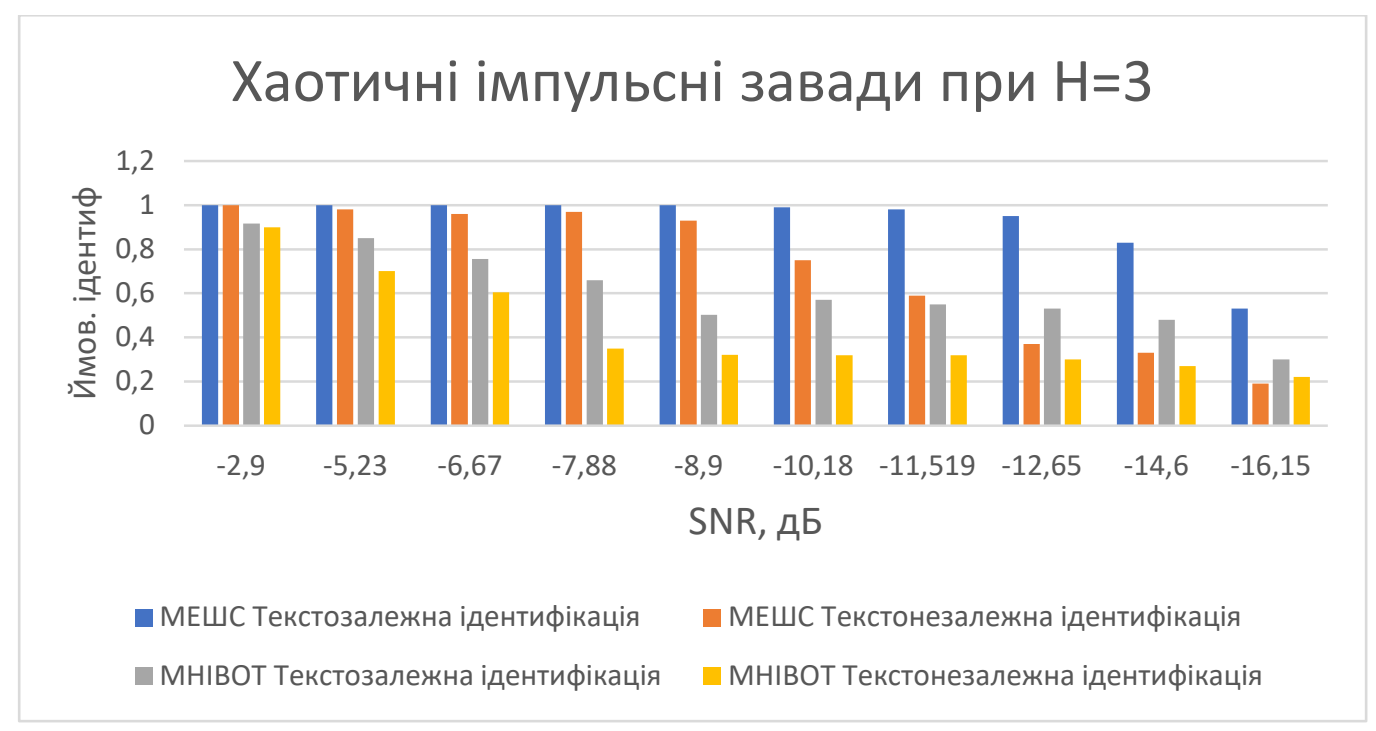

Рис. 5. Показники ймовірності вірної ідентифікації диктора при хаотичних імпульсних завадах розробленими методами при $H=3$ 
Що стосується визначення ймовірності вірної ідентифікації диктора в багатоальтернативних задачах підтримки прийняття рішення при $H=3$ (табл. 3), то в даному випадку методи дають можливість проводити точну ідентифікацію в умовах, коли $S N R=-10,18$ дБ $\quad$ для текстозалежної і при $S N R=-2,9$ дБ для текстоненезалежної ідентифікації методом ефективної ширини спектру. Для методу найбільшої інформаційної ваги основного тону показник $S N R=-2,9$ дБ дає можливість провести ідентифікацію з точністю 90\% для текстонезалежної та з точністю 91\% для текстозалежної ідентифікації (рис. 5).

Таблиця 3

Визначення ймовірності вірної ідентифікації диктора в багатоальтернативних задачах підтримки прийняття

\begin{tabular}{|c|c|c|c|c|}
\multicolumn{4}{c|}{} & \multicolumn{2}{c|}{$\begin{array}{c}\text { Метод } \\
\text { ефективної } \\
\text { шNR, } \\
\text { дБрини спектра }\end{array}$} & $\begin{array}{c}\text { Метод найбільшої } \\
\text { інформаційної ваги } \\
\text { основного тону }\end{array}$ \\
\cline { 2 - 5 } & $\begin{array}{c}\text { Текс- } \\
\text { тозале- } \\
\text { жна } \\
\text { іденти- } \\
\text { фікація }\end{array}$ & $\begin{array}{c}\text { Текс- } \\
\text { тонеза- } \\
\text { лежна } \\
\text { іденти- } \\
\text { фікація }\end{array}$ & $\begin{array}{c}\text { Тексто- } \\
\text { залежна } \\
\text { іднтифі- } \\
\text { кація }\end{array}$ & $\begin{array}{c}\text { Текстоне- } \\
\text { залежна } \\
\text { ідентифі- } \\
\text { кація }\end{array}$ \\
\hline$-2,9$ & 1 & 1 & 0,917 & 0,9 \\
\hline$-5,23$ & 1 & 0,98 & 0,85 & 0,7 \\
\hline$-6,67$ & 1 & 0,96 & 0,755 & 0,604 \\
\hline$-7,88$ & 1 & 0,97 & 0,66 & 0,35 \\
\hline$-8,9$ & 1 & 0,93 & 0,502 & 0,321 \\
\hline$-10,18$ & 0,99 & 0,75 & 0,57 & 0,32 \\
\hline- & 0,98 & 0,59 & 0,55 & 0,32 \\
\hline 11,519 & 0,95 & 0,37 & 0,53 & 0,3 \\
\hline$-12,65$ & 0,83 & 0,33 & 0,48 & 0,27 \\
\hline$-14,6$ & 0,83 & 0,3 & 0,22 \\
\hline$-16,15$ & 0,53 & 0,19 & 0,3 \\
\hline
\end{tabular}

\section{3. Висновок}

Проведена оцінка ефективності розроблених методів дає можливість зробити висновок, що високі показники ідентифікації аудіосигналів у багатоальтернативних задачах підтримки прийняття рішення в інформаційних системах забезпечуються особливостями обраного простору ознак для певних видів завад. Наявність Гаусівського шуму в каналі зв'язку дає можливість текстозалежної ідентифікації з ймовірністю 98\% при $H=8$ та $H=6$ навіть у випадку, коли шум перевищує сигнал у 1,67 разів, а для текстозалежної - у 1,1 разу. Метод найбільшої інформаційної ваги основного тону дає такі показники для $H=8$ та $H=6$ у випадку, коли шум перевищує сигнал у 1,43 разу для текстонезалежної ідентифікації, а для текстозалежної ймовірність 96\% вірної ідентифікації забезпечується, коли сигнал перевищує шум в 1,1 разу. Звичайно, особливість формування хаотичних імпульсних завад значно впливає на показники ідентифікації диктора шляхом використання розроблених методів, так як з простору ознак мовленнєвого сигналу було обрано саме частоту основного тону, а збігання іiі з початковою частотою формування імпульсів значно змінюе інформаційні складові спектрального представлення сигналу, в тому числі і амплітуди обертонів мовленнєвого сигналу. Однак, незважаючи на такий вплив, методи продемонстрували високу ефективність при $H=3$ і дали можливість ідентифікувати мовленнєвий сигнал 3 ймовірністю більше 90\% як для текстозалежного, так і для текстонезалежного випадку при перевищенні шумом використаного сигналу в 0,83 разу.

Література: 1. Юдін О. К., Зюбіна Р. В. Метод ефективної ширини спектру //Наукоємні технології. 2018. Т. 37. №. 1. С. 55- 60. 2. Юдін О. К., Зюбіна Р. В. Класифікація методів ідентифікації частоти основного тону //Наукоємні технології 2017. Т. 33, №. 1. С. 13-21. 3. Юдін О. К., Зюбіна Р. В. Оцінка ефективності методів ефективної ширини спектру та найбільшої інформаційної ваги основного тону в задачах ідентифікації та автентифікації аудіо сигналів // Наукоємні технології 2017. T. 35. №. 3. С. 209-214. 4. Антипенский Р. Разработка моделей преднамеренных помех сигналам с дискретной модуляцией // Компоненты и технологии. 2007. №. 75. С. 138- 143.

Транслітерований список літератури.

1. Judin O. K., Ziubina R. V. Metod efektyvnoi' shyryny spektru // Naukojemni tehnologii' 2018. T. 37, №. 1. S. 5560.

2. Judin O. K., Ziubina R. V. Klasyfikacija metodiv identyfikacii' chastoty osnovnogo tonu // Naukojemni tehnologii' 2017. T. 33, №. 1. S. 13-21.

3. Judin O. K., Ziubina R. V. Ocinka efektyvnosti metodiv efektyvnoi' shyryny spektru ta najbil'shoi' informacijnoi' vagy osnovnogo tonu $\mathrm{v}$ zadachah identyfikacii' ta avtentyfikacii' audio sygnaliv // Naukojemni tehnologii'. 2017. T. 35, №. 3. S. 209-214.

4. Antypenskyj R. Razrabotka modelej prednamerennыh pomeh sygnalam s dyskretnoj moduljacyej // Komponentы y tehnologyy. 2007. №.75. S. 138-143.

Надійшла до редколегії 24.05.2018

Рецензент: д-р техн. наук, проф. Бараннік В.В. Юдін Олександр Костянтинович, д-р техн. наук, проф., директор Навчально-наукового інституту комп'ютерних інформаційних технологій Національного авіаційного університету. Наукові інтереси: інформаційні технології, інформаційна безпека. Адреса: м. Київ, пр. Космонавта Комарова, 1, тел. 406-70-08.

Зюбіна Руслана Віталіївна, ст. викладач кафедри комп'ютеризованих систем захисту інформацій Національного авіаційного університету. Наукові інтереси: інформаційні технології, інформаційна безпека. Адpeca: м. Київ, пр. Космонавта Комарова 1, тел. 406-7008.

Yudin Oleksandr K., Dr of Sc, Prof., Director of the Educational and Scientific Institute of Computer Information Technologies at the National Aviation University. Information technologies, information security. Address: Kyiv, 1 Kosmonavta Komarova av., tel. 406-70-08.

Ziubina Ruslana V., Senior Lecturer at the Department of Computerized Systems of Information Security at the National Aviation University. Information technologies, information security. Address: Kyiv, 1 Kosmonavta Komarova av., tel. 406-70-08. 